Egyptian

Orthodontic Journal

\title{
CLINICAL EVALUATION OF CHAIRSIDE BAND AND LOOP SPACE MAINTAINERS
}

\author{
Nagwa A. Ghoname ${ }^{1}$
}

\section{ABSTRACT:}

The use of space maintainer in the pediatric population has gained increasing attention from researchers. Chairside space maintainers are single setting technique and they are able to save practice time. The purpose of the study was to compare the clinical performance of chairside and conventional band and loop space maintainers. For this clinical trial, fifteen healthy children between the ages of five and eight years with premature loss of mandibular primary first molars were selected from Pedodontic Clinic, Faculty of Dentistry, Tanta University. For the selected children chairside band and loop was applied in one quadrant and conventional band and loop for the other quadrant. The chairside and conventional band and loop space maintainers were adjusted to fit the abutment tooth tightly and to rest against the anterior abutment tooth at the contact area. Both types were then cemented onto clean, dry abutment tooth with glass ionomer cement. All inserted space maintainers were evaluated for one year. The results showed that, the clinical success rate of chairside band and loop space maintainers was $80 \%$ and their mean survival time was11.25months. While conventional band and loop space maintainers showed $73.33 \%$ clinical success rate and10.75 months for the mean survival time. The differences, however, were not statistically significant ( $P>0.05)$. In conclusion: Chairside band and loop space maintainer can be considered a successful appliance for space maintenance.

1 - Associate Professor of Pediatric Dentistry, Faculty of Dentistry, Tanta University 
Egyptian

Orthodontic Journal

\section{INTRODUCTION}

Primary teeth play a critical role in the growth and development of child. In addition to their role in esthetics, eating, speech, they encourage normal function and growth, the other main function of a primary tooth is to hold space for the permanent successor until it is ready to erupt. ${ }^{(1)}$

Premature loss of primary molars often causes undesirable drifting and loss of space; however, immediate insertion of space maintainers to preserve arch length can prevent or limit the malocclusion development. ${ }^{(2)}$

To avoid malocclusion due to premature loss of the primary teeth, clinicians advise various types of space maintainers (removable or fixed appliances), although removable space maintainers have certain advantages, such as being easier to clean and allowing better maintenance of oral hygiene, they may be broken or lost easily and, if they are not used properly, they will not be effective. ${ }^{(3,4)}$

In contrast, fixed appliances, if properly designed, are less damaging to the oral tissues and are less of a nuisance to the patient as well as the dentist because they are worn continuously for a longer period. It has been reported that a well-designed fixed space maintainer is more preferable than a removable appliance to both patient and dentist. ${ }^{(4,5)}$ Among the various space maintainers used in pediatric dentistry, band and loop is the most commonly used fixed space maintainer. ${ }^{(6)}$

Although these fixed appliances are well tolerated and durable, they require impression, laboratory work and prolonged visiting times. In addition, the solder area is fragile and the risk of solder joint failure may increase. ${ }^{(7,8)}$ Also, it was noted that these space maintainers have the potential to submerge into the gingivo-alveolar tissues and tend to lead to tipping and rotating in the abutment teeth. ${ }^{(9,10)}$

These limitations of the conventional type of space maintainers indicate the need for newer materials and designs of the appliances. Some 
Egyptian

Orthodontic Journal

modifications to crown and loop or band and loop were introduced and evaluated clinically. ${ }^{(11-13)}$ Presently, there are few commercially available alternatives to this treatment, such as prefabricated space maintainers. It is a simple chairside procedure whereby space maintainer inserted immediately with the lack of laboratory expenses and elimination of a second visit for appliance insertion. ${ }^{(14,15)}$

So, the current study was done to compare the clinical performance of chairside and conventional band and loop space maintainers.

\section{MATERIALS AND METHODS}

Fifteen healthy children between the ages of five and eight years were included in this clinical trial. The children presented to Pedodontic Clinic, Faculty of Dentistry, Tanta University with bilateral premature loss of primary first molars and they were in need for space maintainers. Parents were informed about the clinical evaluation and informed consents for the children participation were received.

For each child, chairside space maintainer was applied in one quadrant and in the other quadrant band and loop space maintainer was cemented. Oral prophylaxis and other restorative treatment were done prior to the placement of space maintainer.

\section{Application of Chair side Space Maintainer}

The chairside band and loop space maintainer (Denovo Dental, Inc, USA) was adjusted and applied in one visit following the manufacture technique. The correct band size was selected to fit the abutment tooth tightly, the space maintainer wire end (loop) was inserted into tube and trial fit assembly in mouth. The wire was slide to the desired length enough to rest against the anterior abutment tooth at the contact area and the excess was trimmed using a diamond disk (Figure 1,2). The tube was lightly crimped on the inserted wire and the appliance was then checked for stability. The space maintainer was then cemented onto a clean, dry 
abutment tooth with glass ionomer cement (Ketac Cem, ESPE, Seefeld, Germany) in accordance with the recommendations of the manufacturer.

\section{Construction of Conventional Band and Loop Space Maintainer:}

At the initial visit, stainless steel band (3M Co, St. Paul, MN) appropriate for tooth size was selected and contoured to adapt closely to the abutment tooth. The band was then seated on the tooth approximately one millimeter below the mesial and distal marginal ridges, and a full arch impression was taken with alginate impression material. Next, the band was removed from the mouth with band remover and was placed and stabilized in the impression in the correct position; then working model was prepared from dental stone with the band in place. On the cast, the loop was made of $0.8 \mathrm{~mm}$ stainless steel wire; it was designed to approximate the gingival contour of the extraction space to avoid occlusal interferences and extends from the middle of the band from its either side to reach the distal surface of the anterior abutment tooth just below the contact area as shown in figure (3). The loop was then soldered to the band and the joint was finished and polished ${ }^{(16,17)}$. At the second visit, space maintainer was cemented onto a clean, dry abutment tooth with glass ionomer cement (Ketac Cem , ESPE, Seefeld, Germany) as shown in figure $(4,5)$.

The parents were instructed to notify the clinician immediately if the space maintainers became loose, or if any discomfort was encountered. Regular follow up appointments were scheduled every three months for one year. The space maintainers were assessed as lost to follow up, successful and failed (solders breakage, cement lost, loop fracture, soft tissue impingement and interference with successor eruption). ${ }^{(18)}$

All data were processed by SPSS 18.0. Cumulative survival rates of space maintainers were estimated via Kaplan-Meier methods. The median survival time for all space maintainers were tested using Log Rank test. The $\mathrm{p}$ value $<0.05$ was considered significant. 


\section{Egyptian \\ Orthodontic Journal}

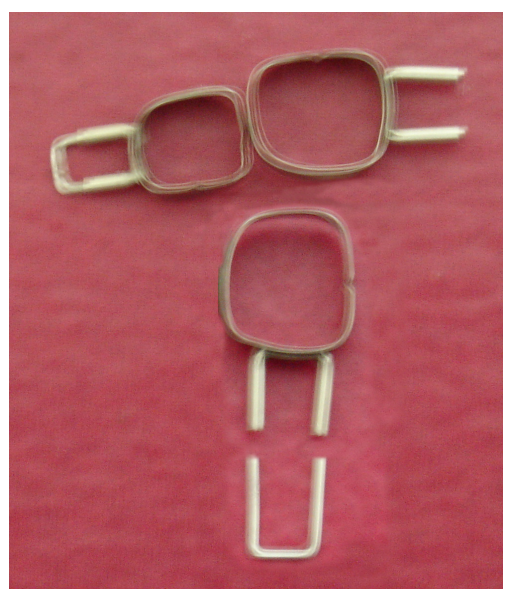

Figure1. Chairside band and loop space maintainer.

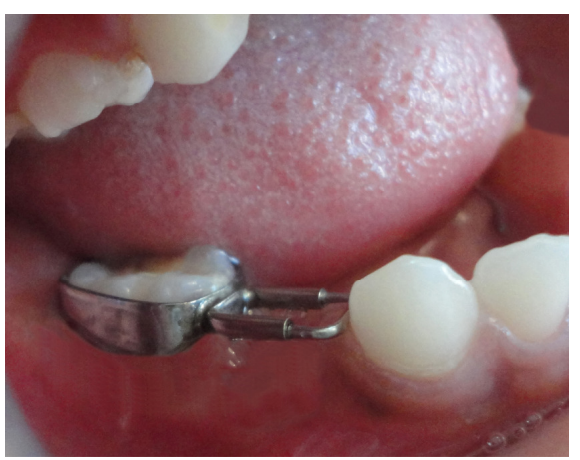

Figure2. Intraoral adjustment of chairside band and loop space maintainer.

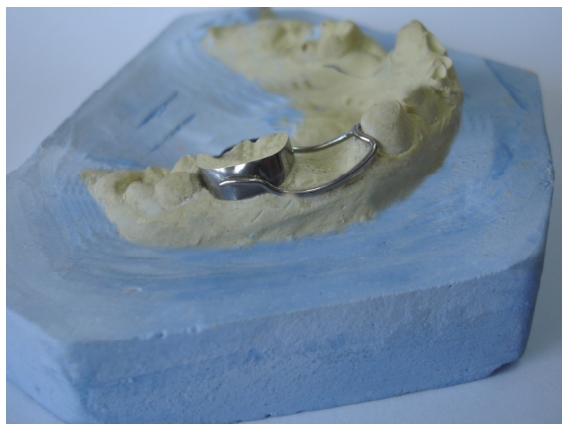

Figure3. Design of conventional band and loop space maintainer on the dental cast.

Volume 43 - June 2013 


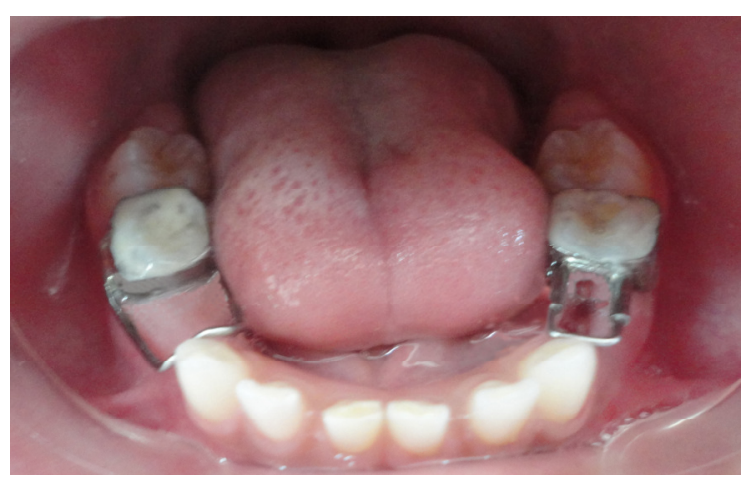

Figure4. Intraoral view of chairside (left side) and conventional (right side) band and loop space maintainers applied bilaterally.

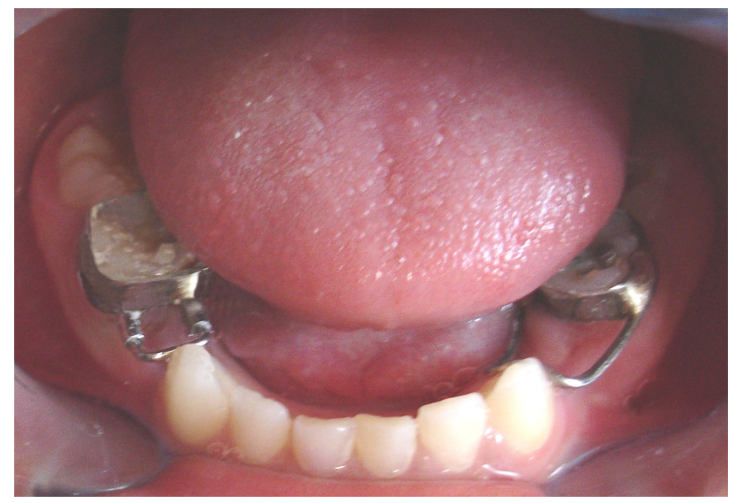

Figure 5. Intraoral view of chairside (right side) and conventional (left side) band and loop space maintainers applied bilaterally.

\section{RESULTS}

Data for fifteen children with thirty space maintainers inserted were available for analysis during the observation period. The distribution of the study sample in relation to age, gender, and type of space maintainers are presented in Table1. The fate of space maintainers is shown in Table 2. For chairside band and loop 2(13.33\%) were considered as failures, 1(6.67\%) reported as lost to attend the follow up appointment and $12(80 \%)$ lasted successfully until the study period ended. For conventional band and loop, $3(20 \%)$ were considered failures, $1(6.67 \%)$ reported as lost to attend the follow up appointment and 11(73.33\%) lasted successfully until the 
study period ended. The causes of failure of the space maintainers are presented in Table (3). The common cause of failure was cement loss in both types; while one conventional band and loop was failed due to solder joint breakage. The mean survival time of chairside band and loop was 11.25 months and 10.75 months for conventional band and loop. There were no statistically significant differences between the mean survival time and overall success rate in both types of space maintainers ( $>0.05)$ (Table 4 and Figure6).

Table1. The distribution of the study sample.

\begin{tabular}{||l||c|}
\hline \multicolumn{1}{||c|}{ Variable } & Distribution \\
\hline \hline Sample size & 15 \\
\hline Girls & 9 \\
\hline Boys & 6 \\
\hline Age (mean ) & $5-8(6.87)$ \\
\hline Chairside band \& loop & 15 \\
\hline Conventional band \& loop & 15 \\
\hline \hline
\end{tabular}

Table2. The fate of chairside and conventional band \& loop space maintainers.

\begin{tabular}{|l||c|c|}
\hline \multirow{2}{*}{\multicolumn{1}{|c|}{ Fate of SMs }} & \multicolumn{2}{|c|}{ Types of SMs } \\
\cline { 2 - 3 } & $\begin{array}{c}\text { Chairside B\&L } \\
\text { No. (\%) }\end{array}$ & $\begin{array}{c}\text { Conventional B\&L } \\
\text { No. (\%) }\end{array}$ \\
\hline \hline Lost to Follow & $1(6.67)$ & $1(6.67)$ \\
\hline Failed & $2(13.33)$ & $3(20.00)$ \\
\hline Success & $12((80)$ & $11(73.33)$ \\
\hline Total & $15(100)$ & $15(100)$ \\
\hline \hline
\end{tabular}

$\mathrm{SMs}=$ space maintainers

$\mathrm{B} \& \mathrm{~L}=$ band and loop 
Egyptian

Orthodontic Journal

Table3. The causes of failure seen with chairside and conventional band \& loop space maintainers.

\begin{tabular}{||l||c||c||}
\hline \multirow{1}{*}{\multicolumn{1}{|c||}{ Cause of failure }} & \multicolumn{2}{c|}{ Types of SMs } \\
\cline { 2 - 3 } & $\begin{array}{c}\text { Chairside B\&L } \\
\text { No. (\%) }\end{array}$ & $\begin{array}{c}\text { Conventional B\&L } \\
\text { No.(\%) }\end{array}$ \\
\hline \hline Cement lost & $2(13.33)$ & $2(13.33)$ \\
\hline Solder breakage & - & $1(6.67)$ \\
\hline Loop fracture & - & - \\
\hline Soft tissue impingement & - & - \\
\hline Interference with successor eruption & - & \\
\hline
\end{tabular}

$\mathrm{SMs}=$ space maintainers

$\mathrm{B} \& \mathrm{~L}=$ band and loop

Table4. Comparison of overall success rate and the mean survival time for chairside and conventional band \& loop space maintainers.

\begin{tabular}{|c|c|c|c|c|c|}
\hline Types of SMs & $\begin{array}{l}\text { Success } \\
\text { rate }\end{array}$ & p-value & $\begin{array}{l}\text { Mean survival } \\
\text { time (months) }\end{array}$ & $\begin{array}{l}\text { Standard } \\
\text { Error }\end{array}$ & p-value \\
\hline Chairside B\&L & $80 \%$ & \multirow{2}{*}{0.98} & 11.25 & \pm 0.63 & \multirow{2}{*}{0.718} \\
\hline Conventional B\&L & $73.33 \%$ & & 10.75 & \pm 0.76 & \\
\hline
\end{tabular}

$\mathrm{SMs}=$ space maintainers

$\mathrm{B} \& \mathrm{~L}=$ band and loop

Volume 43 - June 2013 


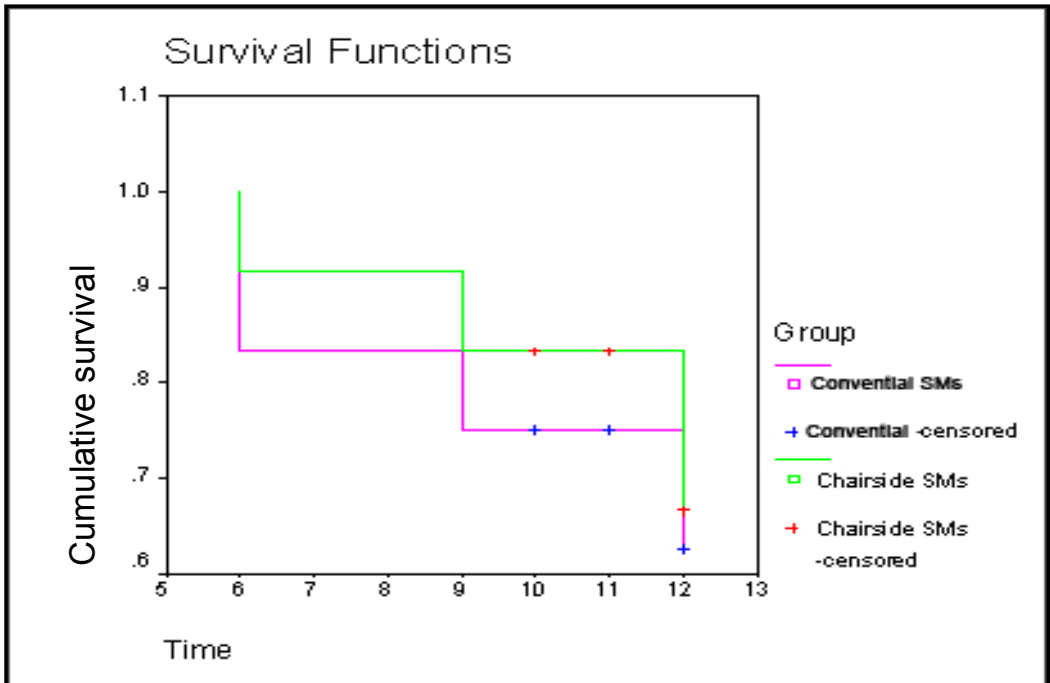

Figure 6. Cumulative survival of space maintainers used in the study in relation to their types.

\section{DISCUSSION}

Space management of the developing occlusion is an important part of interceptive and preventive dental care. The dental profession has recommended the use of space maintainers to reduce the prevalence and severity of malocclusion following premature loss of primary teeth. ${ }^{(19)}$

The appropriate design and application of space maintenance appliances are of most important in primary and mixed dentition. Several new types of space maintainers have been introduced recently such as glass fiber-reinforced composite space maintainer ${ }^{(20,21)}$, simple fixed space maintainer bonded with flowable composite ${ }^{(22)}$, free ended space maintainer ${ }^{(23)}$ and prefabricated space maintainer. ${ }^{(14)}$ However, there has been little comparative clinical evaluation of the different types of space maintainer currently available. Hence, the aim of this study was to compare the clinical performance of both chairside and conventional band and loop space maintainers.

In the present study, conventional band and loop space maintainer was selected for comparison because it is the most commonly used fixed 
Egyptian

Orthodontic Journal

space maintainer for premature loss of primary molars and many researchers advocate its use as it is durable and economical to produce. ${ }^{(13)}$

Since previous studies ${ }^{(24,25)}$ had indicated that mandibular appliances may fail more frequently than maxillary appliances. So, in the present study both types of space maintainers were applied in the lower jaw for each child to be exposed to the same environment as diet, oral hygiene and occlusal forces.

It has been previously documented that the failure rate of conventional band and loop space maintainers varies between $29 \%$ and $57.5 \%$. ${ }^{(26-28)}$ In the current study, the failure rate at 12 month evaluation period was $20 \%$ compared to $24 \%$ reported by Moore and Kennedy. ${ }^{(24)}$ While Baroni et al. ${ }^{(25)}$ and Tunc et al. ${ }^{(29)}$ reported $10 \%$ at 12.5 month and 12 month respectively. The difference in the failure rate may be attributed to the difference in sample size, length of the observation periods and the luting cement used.

On the other hand, the failure rate of chairside band and loop in the present study was lower $(13.33 \%)$ than that of conventional band and loop, this can be explained by the difference in the design and fabrication of chairside space maintainer. This appliance is prefabricated; no need for soldering of the loop and the breakage at the solder joint was eliminated.

A high success rate of chairside band and loop (80\%) in comparison to conventional band and loop (73.33\%) with no statistically significant difference between them was found in the current study. Some studies reported the success rate of band and loop space maintainer to be as high as $90 \%{ }^{(29)}$ and $62 \%,{ }^{(27)}$ while others reported it to be as low as $33 \%{ }^{(30)}$ and $32.3 \%$. ${ }^{(31)}$ This difference may be related to the characteristic of the sample and the long study period.

In this study, cement loss represented the high percentage (13.33\%) of failure in both type of space maintainers, this rate was consistent with the findings of Moore and Kennedy ${ }^{(24)}(15 \%)$ and higher than that reported by Bawazir (8\%). ${ }^{(31)}$ While, Fathian et al., ${ }^{(27)}$ Rajab $^{(26)}$ and Qudeimat \& Fayle ${ }^{(32)}$ reported 19\%, 32\% and 36\% cement failure rates respectively in fixed space maintainers. The cement loss may be related 
to difficulty in achieving complete isolation during cementation, especially in young patients or the anatomy of primary second molar, which may also preclude a tight band fit. ${ }^{(27)}$

The second cause of failure of conventional band and loop space maintainers in the present study was solder breakage which accounted about $6.67 \%$ compared to $7 \%$ reported by Subramaniam et al. ${ }^{(30)}$ and $9 \%$ reported by Sasa et al., ${ }^{(28)}$ however, this rate was lower than the $50 \%$, $37 \%$ and $23 \%$ breakage failure rates reported for fixed space maintainers in previous studies. ${ }^{(26,25,32)}$ This breakage may be attributed to incomplete soldering of joints or overheating of the wire during soldering or over thinning of the wire during polishing or remnants of flux on the wire and failure to encase the wire in the solder. ${ }^{(33,34)}$

The present study showed a satisfactory mean survival time despite the failure rates of both types of space maintainers at the end of twelve month. The mean survival time was 11.25 months and 10.75 months for chairside and conventional band and loop space maintainers respectively. This result is in accordance with Tunc et al. ${ }^{(29)}$ who found that the mean survival time for the band and loop appliances was 11.2 months. While, Rajab et al., ${ }^{(26)}$ Sasa et al. ${ }^{(28)}$ and Fathian et al. ${ }^{(27)}$ reported higher survival time with rates of 18 months, 19.9 months and 26 months respectively for the band and loop appliances. This difference may be related to the design and construction which affected the survival time and longevity of the space maintainer.

In this study, it was noted that both chairside and conventional band \& loop space maintainers were clinically accepted, while chairside type showed increased success rate than conventional band and loop space maintainer. In addition, chairside band and loop space maintainer overcomes the limitations of the conventional type previously reported. ${ }^{(7,}$ 8) The prefabricated chairside appliance can be delivered at single setting with lesser laboratory time, better accuracy and saving the chairside time especially with young children. Future studies with a longer follow up period are recommended. 
Egyptian

Orthodontic Journal

\section{CONCLUSION}

Based on the present results, it was conclude that:

1- Chairside band and loop space maintainers have a satisfactory success rate and mean survival time

2- Chairside and conventional band \& loop space maintainers were clinically accepted.

\section{REFERENCES}

1- Bijoor RR, Kohli K: Contemporary space maintenance for the pediatric patient. NY Stat Dent J 2005; 71:32-35.

2- Ngan P, Alkire RG, Fields H Jr: Management of space problems in the primary and mixed dentitions J Am Dent Assoc1999 ;130:1330-1339.

3- Dincer M, Haydar S, Unsal B, Turk T: Space maintainer effects on intercanine arch width and length. J Clin Pediatr Dent 1996; 21:47-50.

4- Kargul B, Caglar E, Kabalay U: Glass fiber reinforced composite resin space maintainer: Case reports. J Dent Child 2003; 70:258-261.

5- Terlaje RD, Donly KJ: Treatment planning for space maintenance in the primary and mixed dentition. J Dent Child 2001; 2:109-114.

6- Yeluri R, Munshi AK: Fiber reinforced composite loop space maintainer: An alternative to the conventional band and loop. Contemp Clin Dent 2012; 3: S26-S28.

7- Hill CJ, Sorenson HW, Mink JR.: Space maintenance in a child dental program. J Am Den Assoc 1975:90:811-815.

8- Thornton JB. The space maintainer: Case reports of misuse and failures. Gen Dent 1982; 30:64-7.

9- Croll TP: Prevention of gingival submergence of fixed unilateral space maintainers. J Dent Child1982; 49: 48-51.

10- Foster TD: Dental factors affecting occlusal development: A textbook of Orthodontics, London: Blackwell. 1990; pp 129-146. 
11- Santos VL, Almeida MA, Mello HSA, et al.: Direct bonded space maintainers. J Clin Pediatr Dent 1993;17: 221-225.

12- Horax S: Fixed space maintainer with molar band in premature loss of primary first molar teeth(case report). Med Nus 2006; 27: 174-176.

13- Yilmez Y, Kocogullari E, Belduz N: Fixed space maintainer combined with open face stainless steel crowns. J Contemp Dent Pract 2006; 7: 1-8.

14- Nayak UA, Loius J, Sajeev R, Peter J: Band and loop space maintainer-made easy. J Indian Soc Pedod Prev Dent 2004; 22:134-136.

15- Brill WA: The distal shoe space maintainer: Chairside fabrication and clinical performance. Pediatr Dent 2002; 24:561-565.

16- Christensen JR, Fields HW: Space maintenance in the primary dentition. In: Pinkham JR. Pediatric Dentistry: Infancy through adolescence, $4^{\text {th }}$ ed. St. Louis, Saunders. 2005; pp 423-430.

17- Bell RA, Dean JA, McDonald RE, Avery DR: Management of the developing occlusion. In: McDonald RE, Avery DR, Dean JA. Dentistry for the child and adolescent, $9^{\text {th }}$ ed. St. Louis, Mosby.2011; pp 550-613.

18- Tulunoglu O, Ulusu T, Genc Y: An evaluation of survival of space maintainers: A six-year follow- up study. J Contemp Dent Pract 2005; 15: 74-84.

19- Mitchell L and Mitchell DA: Oxford handbook of clinical dentistry. $3^{\text {rd }}$ ed. Oxford: University Press. 1999; pp 128-198

20- Kulkarni G, Lau D, Hafezi S: Development and testing of fiber-reinforced composite space maintainers. J Dent Child 2009; 76:204-248.

21- Verma KG, Verma P: Esthetics in space management - demand of new era. IJDA 2011; 3: 549-551.

22- Simsek S, Yilmaz Y, Gurbuz T: Clinical evaluation of simple fixed space maintainers bonded with flow composite resin. J Dent Child 2004; 71:163-168. 
Egyptian

Orthodontic Journal

23- Barbería E, Lucavechi T, Cárdenas D, Maroto M: Free-end space maintainers: design, utilization and advantages. J Clin Pediatr Dent 2006; 31:5-8.

24- Moore T R, Kennedy, D B: Bilateral space maintainers: A 7-year retrospective study from private practice. Pediatr Dent 2006; 28: 499-505.

25- Baroni C, Franchini A, Rimondini L: Survival of different types of space maintainers. Pediatr Dent.1994; 16:360-361.

26- Rajab LD: Clinical performance and survival of space maintainers: Evaluation over a period of 5 years. J Dent Child.2002; 69:156-160.

27- Fathian M, Kennedy DB, Nouri MR: Laboratory-made space maintainers: a 7 years retrospective study from private pediatric dental practice. Pediatr Dent 2007; 29:500-506.

28- Sasa IS, Hasan AA, QudeimatMA : Longevity of band and loop space maintainers using glass ionomer cement: A prospective study. Eur Arch Paediatr Dent2009; 10: 6-10.

29- Tunc ES, Bayrak S, Tuloglu N, et al.: Evaluation of survival of 3 different fixed space maintainers. Pediatr Dent 2012; 34:97-102.

30- Subramaniam P, Babu GKL, Sunny R: Glass fiber-reinforced composite resin as a space maintainer: A clinical study J Indian Soc Pedod Prev Dent 2008;26:98-103.

31- Bawazir O: Evaluation of space maintainers fabricated by dental students: a retrospective study. Pakistan Oral Dent J 2009; 29:357-360.

32-Qudeimat MA and Fayle SA: The longevity of space maintainers: a retrospective study. Pediatr Dent 1998; 20: 267-272.

33- Wright GZ, Kennedy DB: Space control in the primary and mixed dentitions. Dent Clin North Am 1978; 22:579-601.

34- Finn SB. Clinical pedodontics. $4^{\text {th }}$ ed. Philadelphia: W.B. Sandures Company. 1998; p.354. 